\title{
Synthesis of self-healing Smart Epoxy and Polyurethane Coating by Encapsulation of Olive Leaf Extract as Corrosion Inhibitor
}

\author{
Zahra Jamshidnejad*, Abdollah Afshar, Mohammad Amin RazmjooKhollari \\ Department of Materials Science and Engineering, Sharif University of Technology Address: Azadi \\ Avenue, 14588 Tehran, Iran \\ *E-mail: Zahrajamshidnejad@yahoo.com
}

doi: $10.20964 / 2018.12 .83$

Received: 28 August 2018 / Accepted: 8 October 2018 / Published: 5 November 2018

\begin{abstract}
Self-healing coatings with the ability of recovering damaged areas, have a high potential application in corrosion prevention, because of high reliability and cost reductions. In this research, fabrication and characterization of epoxy and urethane based self-healing coatings by encapsulation of olive leaf extract as corrosion inhibitor are investigated. HOPDMS and PDES were used as healing agents in urethane shelled capsules. Moreover, olive leaf extract was added to the healing capsules to further increase the corrosion protection of the coating. By means of polarization and electrochemical impedance spectroscopy tests, it was proved that the olive leaf extract is an effective corrosion inhibitor for steel in chloride solutions, with an inhibition efficiency of about $80 \%$ for ethanol extracted inhibitor at $300 \mathrm{ppm}$. Submicron capsules containing inhibitor and healing agents were fabricated by simultaneous agitation and sonication, and were characterized by SEM, EDS and FTIR analyzes. Finally, the self-healing ability of the coatings containing 3,4, and 5 percent of capsules were studied, and it was found out that with increasing of capsules content of the coating, the corrosion protection improves, so that in a coating with $5 \mathrm{wt} \%$ of capsules, no evidence of corrosion was observed in the adjacent area of a damage.
\end{abstract}

Keywords:corrosion; self-healing coating; olive leaf extract; green inhibitor;

\section{FULL TEXT}

(C) 2018 The Authors. Published by ESG (www.electrochemsci.org). This article is an open access article distributed under the terms and conditions of the Creative Commons Attribution license (http://creativecommons.org/licenses/by/4.0/). 